\title{
Prediction of neuropsychological outcome after resection of temporal and extratemporal seizure foci
}

\author{
Mario F. Dulay, Ph.D., ${ }^{1}$ And Robyn M. Busch, Ph.D. ${ }^{2}$ \\ ${ }^{I}$ Comprehensive Epilepsy Program and Department of Neurosurgery, The Methodist Hospital Neurological \\ Institute, Houston, Texas; and ${ }^{2}$ Epilepsy Center, Neurological Institute, Cleveland Clinic, Cleveland, Ohio
}

\begin{abstract}
Resection of seizure foci is an effective treatment for the control of medically intractable epilepsy. However, cognitive morbidity can occur as a result of surgical intervention. This morbidity is dependent on several factors, including location and extent of resection, disease characteristics, patient demographic characteristics, and functional status of the tissue to be resected. In this review article, the authors provide a summary of the neurocognitive outcomes of epilepsy surgery with an emphasis on presurgical predictors of postsurgical cognitive decline.
\end{abstract} (http://thejns.org/doi/abs/10.3171/2012.1.FOCUS11340)

\section{KeY WoRdS • neuropsychology • memory • postsurgical outcome • epilepsy}

$\mathrm{E}$ PILEPSY affects approximately $1 \%$ of the US population. Thirty percent of patients who present to epilepsy specialty centers are diagnosed with intractable epilepsy and undergo a comprehensive evaluation for possible surgical intervention for seizure control. A diagnostic workup for surgical intervention includes medical and psychiatric history, neurological examination, videoelectroencephalographic monitoring, structural MRI and other neuroradiological techniques, and neuropsychological testing. Neuropsychological assessment helps to identify patients at risk for cognitive decline following epilepsy surgery.

Resection of seizure foci is an effective treatment for medically intractable epilepsy. Of individuals who undergo unilateral ATR, the most common form of surgery for intractable epilepsy, between $66 \%$ and $70 \%$ achieve seizure freedom..$^{59}$ Of patients with seizures originating from the frontal lobe, approximately $57 \%$ are seizure free 1 year after surgery and $30 \% 5$ years after surgery. ${ }^{32}$ Resection not only has the potential to cure intractable epilepsy, but also can significantly improve health-related quality of life $\mathrm{e}^{57}$ and independence in activities of daily living, ${ }^{35}$ increase the likelihood of return to work, ${ }^{17}$ and improve cognitive functioning. ${ }^{58}$ Problematically, in a subset of patients, resection can contribute to postoperative neurocognitive impairment and emotional disturbance. ${ }^{44,58}$ In this review article, we

Abbreviations used in this paper: $\mathrm{ATR}=$ anterior temporal lobe resection; fMRI = functional MRI. provide a summary of the neurocognitive outcome of epilepsy surgery with an emphasis on presurgical predictors of postsurgical cognitive decline.

\section{Memory After Left ATR}

Verbal memory decline is the most consistently found impairment after left ATR ${ }^{25}$ Sections of the hippocampus and parahippocampal gyrus, removed as part of a standard ATR, are important for encoding and retrieval of verbal information for recent events. Between 22\% and 63\% of individuals who undergo left ATR experience a significant decline in verbal memory, while about $7 \%$ show improvement. ${ }^{58}$ In contrast, between $10 \%$ and $34 \%$ of patients show improvement in verbal memory after right ATR..$^{58}$ The primary predictor of postsurgical verbal memory loss following left ATR is the presurgical functional status of the tissue to be resected. Functional integrity of the mesial temporal lobe can be estimated in a number of ways, including greater left medial temporal lobe activation during presurgical fMRI, ${ }^{6}$ the absence of structural MRI abnormalities such as mesial temporal sclerosis, ${ }^{63}$ a lack of significant asymmetry in temporal lobe activation on FDG-PET,22 and intact presurgical verbal memory ability on neuropsychological ${ }^{9}$ or Wada testing. ${ }^{3}$ Later age at seizure onset is also associated with greater risk for memory decline following ATR, because individuals who have seizures that began in adulthood have a greater likelihood of developing adequate verbal memory abilities prior to the onset of seizures. ${ }^{54}$ 
Postsurgical verbal memory loss after left ATR is also predicted by poor seizure control after surgery, ${ }^{53}$ more extensive resection, ${ }^{26}$ male sex (hypothesized to result because women have a more bilateral representation of memory), ${ }^{62}$ and older age at surgery. ${ }^{30}$ The latter finding is presumed to reflect reduced plasticity or lower compensatory reserve in older adults. ${ }^{1}$ Finally, individuals with moderate depressive symptoms before surgery are at greater risk of verbal memory decline following left ATR; this finding is hypothesized to reflect reduced compensatory reserve. ${ }^{8} \mathrm{Ta}-$ ble 1 summarizes the presurgical predictors of postsurgical memory decline.

\section{Memory After Right ATR}

Visual memory impairments (for example, memory for faces or places) occur in approximately $6 \%-32 \%$ of individuals who undergo right ATR, depending on the type of visual memory. For example, a recent study showed that 1 in 5 individuals who underwent right ATR had a significant decline in face memory ability, whereas 1 in 4 individuals had a decline in memory for spatial locations.${ }^{15}$ As with verbal memory decline after left ATR, postsurgical visual memory loss is predicted by estimating the presurgical functional status of the tissue to be resected. Postsurgical visual memory loss after right ATR is predicted by greater presurgical right medial temporal lobe activation in response to a nonverbal task on fMRI, ${ }^{31}$ a relatively larger right hippocampus compared with the left hippocampus, ${ }^{63}$ later age at seizure onset, ${ }^{21}$ and intact presurgical visual memory ability on neuropsychological ${ }^{20}$ or Wada testing. ${ }^{42}$ Other predictors include side of surgery (nondominant temporal lobe), ${ }^{15}$ larger right lateral neocortex and mesial temporal excision, ${ }^{37}$ poor postoperative seizure control, ${ }^{16}$ and pathology of the resected tissue (atypical hippocampal sclerosis) ${ }^{65}$ Besides visual memory, right ATR is found to impair olfactory discrimination, identification, and recognition memory abilities. ${ }^{45}$

\section{Language After Left ATR}

Word-finding difficulties also occur after ATR to the language-dominant hemisphere. The most common ap- proach to assessing word-finding difficulties, confrontation naming (also referred to as semantic memory), evaluates general facts and meanings acquired through experience. Between 29\% and 54\% of individuals who undergo dominant, left ATR show significant word-finding difficulties after surgery. ${ }^{58}$ Postoperative word-finding difficulties are more likely to occur with more extensive resection of lateral temporal cortex, ${ }^{29}$ which is one area that stores semantic knowledge. ${ }^{24}$ Other predictors of postoperative word-finding difficulties include an absence of hippocampal sclerosis or other imaging abnormalities before surgery, ${ }^{11} \mathrm{MR}$ tractography showing more lateralized white matter tracts in the language-dominant hemisphere, ${ }^{48}$ fMRI temporal lobe laterality index, ${ }^{51}$ the absence of risk factors for seizures (for example, febrile seizures in childhood) ${ }^{56}$ cessation of language in tissue to be resected during intraoperative electrical stimulation mapping, ${ }^{23}$ and better presurgical naming ability. ${ }^{10}$ Semantic knowledge acquired later in life is the most vulnerable to loss after surgery. ${ }^{4}$

Later age at seizure onset is also a valid predictor of naming decline. ${ }^{50}$ Individuals who experience seizures beginning at a later age routinely have better presurgical naming ability, so they are at greater risk of naming difficulties after dominant ATR. Schwarz et al..$^{56}$ found that individuals who had seizure onset at 15 years of age or older were more likely to experience word-finding difficulties than those whose seizures started earlier. It may be that individuals with earlier age at seizure onset have less to lose after surgery because naming ability is already impaired or, alternatively, that brain functions have had the opportunity to reorganize in individuals whose seizures began early in life.

We recently conducted a study to evaluate the risk of naming decline after surgery as a function of age across the lifespan. ${ }^{14}$ We divided a sample of 229 individuals who underwent unilateral ATR (118 left and 101 right) into 5 groups (age at seizure onset $<10,10-19,20-29,30-39$, or $\geq 40$ years). Results showed that the risk of naming decline after left ATR increased as a function of patient age at seizure onset, especially in middle adulthood (see Fig. 1). Over $60 \%$ of patients who had disease onset beginning after the age of 40 years showed a significant decline in

TABLE 1: Predictors of memory outcome after ATR

\begin{tabular}{ll}
\hline \multicolumn{1}{c}{ Predictors of Verbal Memory Decline } & \multicolumn{1}{c}{ Predictors of Visual Memory Decline } \\
\hline dominant, It ATR & nondominant, rt ATR \\
greater pre-ATR It temporal lobe fMRI activation & greater pre-ATR rt temporal lobe fMRI activation \\
absence of hippocampal sclerosis & larger rt hippocampus \\
good preop verbal memory & good preop visual memory \\
good preop Wada verbal memory w/ rt-side injection & good preop Wada visual memory w/ It-side injection \\
no asymmetry in activation on PET scan & later age at seizure onset \\
later age at seizure onset & poor postop seizure control \\
poor postop seizure control & larger rt-lateral neocortex \& mesial temporal excision \\
more extensive resection & pathology of resected tissue (atypical sclerosis) \\
male sex & \\
older age at op & \\
preop major depression & \\
\hline
\end{tabular}




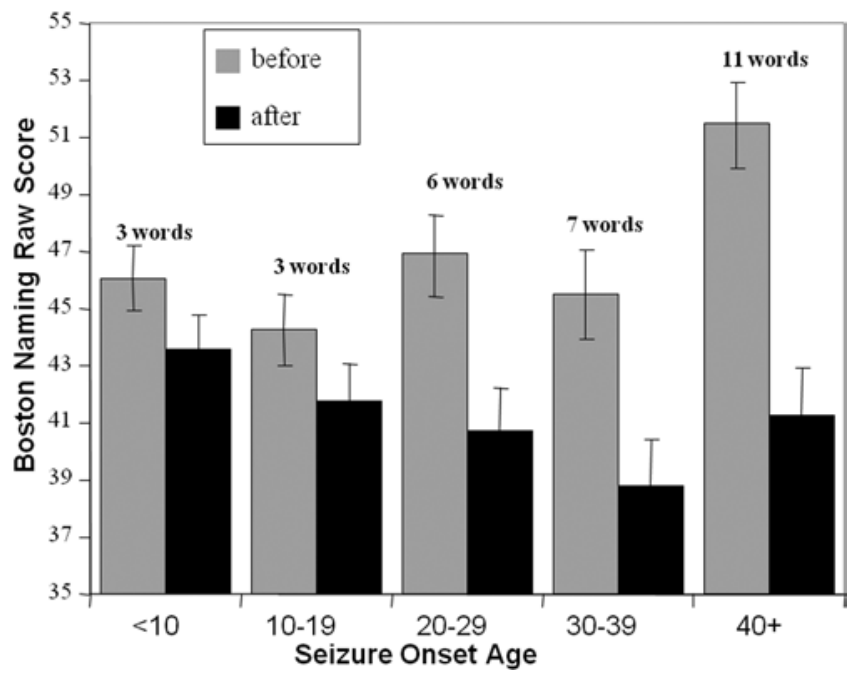

FIG. 1. Graph showing the reduction in naming ability (rounded to closest number of words) from before to after a left ATR stratified by age group (age at which patients began to have seizures). The results show that older age at seizure onset is a risk factor for greater naming decline (11-word decline or $19 \%$ reduction in performance) after left ATR. The bars represent the mean scores for the different age groups.

naming ability after left ATR (Fig. 2), whereas less than $5 \%$ in the same age at seizure onset group showed decline after right ATR. Follow-up analyses demonstrated that it was not that older surgical candidates were more likely to show a decline in naming after surgery but rather older age at seizure onset increased the risk of postsurgical decline.

\section{Executive Function After Frontal Lobe Resection}

The primary predictor of any impairment after frontal lobe resection is the location of surgery. Specific neurological deficits occur when resection involves the primary motor cortex, supplementary motor area, frontal eye fields, Broca area, dorsolateral prefrontal cortex, orbitofrontal cortex, or operculum. Motor and executive functioning impairments are the hallmark deficits associated with frontal lobe resection. Postoperative executive functioning declines following frontal lobe resection may include changes in attention and multitasking, fluency, response inhibition, concept formation, or problem solving. ${ }^{7}$ Left dorsolateral frontal lobe resection is associated with
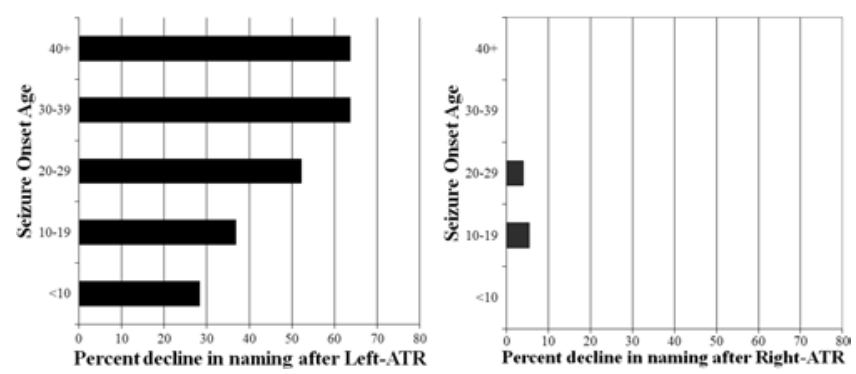

FIG. 2. Left: Graph showing the percentage of individuals who underwent left ATR and experienced a significant decline in naming ability divided by age group (age that patients began to have seizures). Over $60 \%$ of patients with seizure onset later than 30 years of age had a significant decline in naming ability after left ATR. Right: Graph showing the results after right ATR. postoperative phonemic fluency impairment, and right frontal lobe resection is associated with postoperative visual fluency impairment, particularly when the resection is extensive and includes frontal pole and orbitofrontal cortex. ${ }^{36,49}$ Resection that includes dorsolateral prefrontal cortex can also lead to working memory and multitasking deficits ${ }^{40}$ Left-sided resection of frontal premotor and supplemental motor areas is associated with transient expressive aphasia. Larger resections in either hemisphere also contribute to postoperative disinhibition and perseverative behavior. ${ }^{27,49}$ Odor identification and odor memory impairments occur following resection of orbitofrontal cortex. ${ }^{38}$ There is also literature demonstrating executive dysfunction after ATR, which is hypothesized to result from a disconnection between frontal and temporal lobe networks. ${ }^{2}$ Interestingly, a recent case study found that right posterior inferior frontal lobe resection led to transient hemispatial neglect..$^{60}$

Other predictors of executive impairments after frontal lobe resection include intact presurgical executive functioning, ${ }^{27}$ continued seizures after surgery, ${ }^{27}$ and presurgical depressed mood. ${ }^{13}$

\section{Deficits After Occipital and Parietal Lobe Resection}

There is a paucity of research evaluating the cognitive sequelae associated with resection of occipital and parietal lobe seizure foci, and most available studies are based on small samples of heterogeneous patient populations..$^{5,7}$ Given this situation, we focus on summarizing neurological deficits that frequently accompany resections within the occipital or parietal lobes. Patients with occipital lobe epilepsy often have visual symptoms even prior to epilepsy surgery, including visual agnosia, visual hallucinations or illusions, and contralateral visual field defects. ${ }^{18,41,47}$ Visual-cognitive difficulties after occipital lobe resection are usually attributed to damage to optic radiations and other visual processing areas during surgery. A recent report indicated that $50 \%$ of patients had new visual deficits following occipital lobe resection with $17 \%$ developing quadrantanopia or hemianopia. ${ }^{61}$ In one study, 4 of 12 patients who underwent occipital lobe resection sustained new visual field cuts following surgery, and an additional 2 patients reported postoperative change in motion detection ability (that is, with damage to area V5/MT) ${ }^{33}$ In a case study involving a 23-year-old woman, right-sided resection at the inferolateral temporo-occipital junction led to transient prosopagnosia, which resolved 7 days after the surgery.46 Another case study described new-onset implicit visual memory and font-specific priming deficits after a right occipital lobe resection involving Brodmann areas 17 and 18 and a portion of area $19 . .^{19,64}$

Parietal lobe epilepsy is associated with visual perceptual and spatial-constructional impairments, agnosia, decreased tactile discrimination ability contralateral to the side of surgery, left-right orientation confusion, hemineglect, and visual illusions. ${ }^{12,34,52}$ Resection of the parietal lobe can also lead to anomia, agraphia, alexia, apraxia, acalculia, and face-perception difficulties in a small percentage of patients. ${ }^{39,52}$ One study demonstrated that resec- 
tion within posterior temporal-occipital-parietal areas for treatment of epilepsy resulted in a postoperative decline in nonverbal IQ, but not verbal IQ, as nonverbal skills rely to a greater degree on visual processes. ${ }^{43}$

\section{Conclusions}

Cognitive morbidity following resection for treatment of intractable epilepsy is associated with several factors, including location and extent of resection, disease characteristics, patient demographic characteristics, and functional status of the tissue to be resected. Preoperative neuropsychological assessment is useful for creating a risk-benefit profile when estimating the possible postsurgical decrements associated with excision of eloquent areas of the brain versus the benefits of seizure freedom. Presurgical counseling, as well as postsurgical rehabilitation referrals, could diminish any distress associated with deficits that may occur after resection of temporal and extratemporal seizure foci. ${ }^{28,55}$

\section{Disclosure}

The authors report no conflict of interest concerning the materials or methods used in this study or the findings specified in this paper.

Author contributions to the study and manuscript preparation include the following. Conception and design: both authors. Acquisition of data: both authors. Analysis and interpretation of data: Dulay. Drafting the article: both authors. Critically revising the article: both authors. Reviewed submitted version of manuscript: both authors. Approved the final version of the manuscript on behalf of all authors: Dulay. Statistical analysis: Dulay.

\section{References}

1. Baxendale S, Thompson P, Harkness W, Duncan J: Predicting memory decline following epilepsy surgery: a multivariate approach. Epilepsia 47:1887-1894, 2006

2. Bell B, Lin JJ, Seidenberg M, Hermann B: The neurobiology of cognitive disorders in temporal lobe epilepsy. Nat Rev Neurol 7:154-164, 2011

3. Bell BD, Davies KG, Haltiner AM, Walters GL: Intracarotid amobarbital procedure and prediction of postoperative memory in patients with left temporal lobe epilepsy and hippocampal sclerosis. Epilepsia 41:992-997, 2000

4. Bell BD, Davies KG, Hermann BP, Walters G: Confrontation naming after anterior temporal lobectomy is related to age of acquisition of the object names. Neuropsychologia 38:83-92, 2000

5. Binder DK, Von Lehe M, Kral T, Bien CG, Urbach H, Schramm J, et al: Surgical treatment of occipital lobe epilepsy. J Neurosurg 109:57-69, 2008

6. Binder JR: Preoperative prediction of verbal episodic memory outcome using FMRI. Neurosurg Clin N Am 22:219-232, ix, 2011

7. Busch RM: Neuropsychological outcomes of extratemporal surgery, in Helmstaedter C, Hermann B, Lassonde M, et al (eds): Neuropsychology in the Care of People with Epilepsy. Progress in Epileptic Disorders. Montrouge, France: John Libbey Eurotext, 2011, pp 223-237

8. Busch RM, Dulay MF, Kim KH, Chapin JS, Jehi L, Kalman $\mathrm{CC}$, et al: Pre-surgical mood predicts memory decline after anterior temporal lobe resection for epilepsy. Arch Clin Neuropsychol 26:739-745, 2011

9. Chelune GJ, Najm IM: Risk factors associated with postsurgi- cal decrements in memory, in Lüders HO, Comair YG (eds): Epilepsy Surgery, ed 2. Philadelphia: Lippincott Williams \& Wilkins, 2001, pp 497-504

10. Chelune GJ, Naugle RI, Lüders H, Awad IA: Prediction of cognitive change as a function of preoperative ability status among temporal lobectomy patients seen at 6-month followup. Neurology 41:399-404, 1991

11. Davies KG, Bell BD, Bush AJ, Hermann BP, Dohan FC Jr, Jaap AS: Naming decline after left anterior temporal lobectomy correlates with pathological status of resected hippocampus. Epilepsia 39:407-419, 1998

12. Djordjevic J, Jones-Gotman M: Psychological testing in presurgical evaluation of epilepsy, in Shorvon S, Perucca E, Fish D, et al (eds): The Treatment of Epilepsy, ed 2. Oxford: Blackwell Science, 2004, pp 699-715

13. Dulay MF, Busch RM, Smerz JM, Haut JS, Naugle RI, Bingaman W, et al: Depression and executive functioning after unilateral frontal lobectomy. J Int Neuropsychol Soc 13 (Suppl S1):261, 2007 (Abstract)

14. Dulay MF, Chapin JS, Busch RM: Semantic knowledge loss after surgery for adulthood onset intractable epilepsy. J Int Neuropsychol Soc 15 (Suppl S1):4-5, 2009 (Abstract)

15. Dulay MF, Levin HS, York MK, Li X, Mizrahi EM, Goldsmith I, et al: Changes in individual and group spatial and verbal learning characteristics after anterior temporal lobectomy. Epilepsia 50:1385-1395, 2009

16. Dulay MF, Levin HS, York MK, Mizrahi EM, Verma A, Goldsmith I, et al: Predictors of individual visual memory decline after unilateral anterior temporal lobe resection. Neurology 72:1837-1842, 2009

17. Dulay MF, York MK, Soety EM, Hamilton WJ, Mizrahi EM, Goldsmith IL, et al: Memory, emotional and vocational impairments before and after anterior temporal lobectomy for complex partial seizures. Epilepsia 47:1922-1930, 2006

18. Eriksson K, Kylliäinen A, Hirvonen K, Nieminen P, Koivikko M: Visual agnosia in a child with non-lesional occipito-temporal CSWS. Brain Dev 25:262-267, 2003

19. Fleischman DA, Vaidya CJ, Lange KL, Gabrieli JD: A dissociation between perceptual explicit and implicit memory processes. Brain Cogn 35:42-57, 1997

20. Gleissner U, Helmstaedter C, Schramm J, Elger CE: Memory outcome after selective amygdalohippocampectomy: a study in 140 patients with temporal lobe epilepsy. Epilepsia 43:87-95, 2002

21. Goldstein LH, Polkey CE: Short-term cognitive changes after unilateral temporal lobectomy or unilateral amygdalo-hippocampectomy for the relief of temporal lobe epilepsy. J Neurol Neurosurg Psychiatry 56:135-140, 1993

22. Griffith HR, Perlman SB, Woodard AR, Rutecki PA, Jones JC, Ramirez LF, et al: Preoperative FDG-PET temporal lobe hypometabolism and verbal memory after temporal lobectomy. Neurology 54:1161-1165, 2000

23. Hamberger MJ: Cortical language mapping in epilepsy: a critical review. Neuropsychol Rev 17:477-489, 2007

24. Hamberger MJ, Cole J: Language organization and reorganization in epilepsy. Neuropsychol Rev 21:240-251, 2011

25. Hamberger MJ, Drake EB: Cognitive functioning following epilepsy surgery. Curr Neurol Neurosci Rep 6:319-326, 2006

26. Helmstaedter C, Elger CE: Cognitive consequences of twothirds anterior temporal lobectomy on verbal memory in 144 patients: a three-month follow-up study. Epilepsia 37:171-180, 1996

27. Helmstaedter C, Gleissner U, Zentner J, Elger CE: Neuropsychological consequences of epilepsy surgery in frontal lobe epilepsy. Neuropsychologia 36:681-689, 1998

28. Helmstaedter C, Loer B, Wohlfahrt R, Hammen A, Saar J, Steinhoff BJ, et al: The effects of cognitive rehabilitation on memory outcome after temporal lobe epilepsy surgery. Epilepsy Behav 12:402-409, 2008 
29. Hermann BP, Perrine K, Chelune GJ, Barr W, Loring DW, Strauss E, et al: Visual confrontation naming following left anterior temporal lobectomy: a comparison of surgical approaches. Neuropsychology 13:3-9, 1999

30. Hermann BP, Seidenberg M, Haltiner A, Wyler AR: Relationship of age at onset, chronologic age, and adequacy of preoperative performance to verbal memory change after anterior temporal lobectomy. Epilepsia 36:137-145, 1995

31. Janszky J, Jokeit H, Kontopoulou K, Mertens M, Ebner A, Pohlmann-Eden B, et al: Functional MRI predicts memory performance after right mesiotemporal epilepsy surgery. Epilepsia 46:244-250, 2005

32. Jeha LE, Najm I, Bingaman W, Dinner D, Widdess-Walsh P, Lüders H: Surgical outcome and prognostic factors of frontal lobe epilepsy surgery. Brain 130:574-584, 2007

33. Jobst BC, Williamson PD, Thadani VM, Gilbert KL, Holmes GL, Morse RP, et al: Intractable occipital lobe epilepsy: clinical characteristics and surgical treatment. Epilepsia 51:23342337,2010

34. Jokeit H, Schacher M: Neuropsychological aspects of type of epilepsy and etiological factors in adults. Epilepsy Behav 5 (Suppl 1):S14-S20, 2004

35. Jones JE, Berven NL, Ramirez L, Woodard A, Hermann BP: Long-term psychosocial outcomes of anterior temporal lobectomy. Epilepsia 43:896-903, 2002

36. Jones-Gotman M: Localization of lesions by psychological testing. Epilepsia 32 (Suppl 5):S41-S52, 1991

37. Jones-Gotman M: Memory for designs: the hippocampal contribution. Neuropsychologia 24:193-203, 1986

38. Jones-Gotman M, Zatorre RJ: Odor recognition memory in humans: role of right temporal and orbitofrontal regions. Brain Cogn 22:182-198, 1993

39. Kasowski HJ, Stoffman MR, Spencer SS, Spencer DD: Surgical management of parietal lobe epilepsy. Adv Neurol 93:347356,2003

40. Kho KH, Rutten GJ, Leijten FS, van der Schaaf A, van Rijen PC, Ramsey NF: Working memory deficits after resection of the dorsolateral prefrontal cortex predicted by functional magnetic resonance imaging and electrocortical stimulation mapping. Case report. J Neurosurg 106 (6 Suppl):501-505, 2007

41. Lee SK, Lee SY, Kim KK, Hong KS, Lee DS, Chung CK: Surgical outcome and prognostic factors of cryptogenic neocortical epilepsy. Ann Neurol 58:525-532, 2005

42. Lineweaver TT, Morris HH, Naugle RI, Najm IM, Diehl B, Bingaman W: Evaluating the contributions of state-of-the-art assessment techniques to predicting memory outcome after unilateral anterior temporal lobectomy. Epilepsia 47:1895-1903, 2006

43. Luerding R, Boesebeck F, Ebner A: Cognitive changes after epilepsy surgery in the posterior cortex. J Neurol Neurosurg Psychiatry 75:583-587, 2004

44. Macrodimitris S, Sherman EM, Forde S, Tellez-Zenteno JF, Metcalfe A, Hernandez-Ronquillo L, et al: Psychiatric outcomes of epilepsy surgery: a systematic review. Epilepsia 52: 880-890, 2011

45. Martinez BA, Cain WS, de Wijk RA, Spencer DD, Novelly RA, Sass KJ: Olfactory functioning before and after temporal lobe resection for intractable seizures. Neuropsychology 7:351-363, 1993

46. Mesad S, Laff R, Devinsky O: Transient postoperative prosopagnosia. Epilepsy Behav 4:567-570, 2003

47. Pfaender M, D’Souza WJ, Trost N, Litewka L, Paine M, Cook M: Visual disturbances representing occipital lobe epilepsy in patients with cerebral calcifications and coeliac disease: a case series. J Neurol Neurosurg Psychiatry 75:1623-1625, 2004

48. Powell HW, Parker GJ, Alexander DC, Symms MR, Boulby $\mathrm{PA}$, Barker GJ, et al: Imaging language pathways predicts postoperative naming deficits. J Neurol Neurosurg Psychiatry 79:327-330, 2008
49. Risse GL: Cognitive outcomes in patients with frontal lobe epilepsy. Epilepsia 47 (Suppl 2):87-89, 2006

50. Ruff IM, Swanson SJ, Hammeke TA, Sabsevitz D, Mueller WM, Morris GL: Predictors of naming decline after dominant temporal lobectomy: age at onset of epilepsy and age of word acquisition. Epilepsy Behav 10:272-277, 2007

51. Sabsevitz DS, Swanson SJ, Hammeke TA, Spanaki MV, Possing ET, Morris GL III, et al: Use of preoperative functional neuroimaging to predict language deficits from epilepsy surgery. Neurology 60:1788-1792, 2003

52. Salanova V, Andermann F, Rasmussen T, Olivier A, Quesney LF: Parietal lobe epilepsy. Clinical manifestations and outcome in 82 patients treated surgically between 1929 and 1988. Brain 118:607-627, 1995

53. Sanyal SK, Chandra PS, Gupta S, Tripathi M, Singh VP, Jain $S$, et al: Memory and intelligence outcome following surgery for intractable temporal lobe epilepsy: relationship to seizure outcome and evaluation using a customized neuropsychological battery. Epilepsy Behav 6:147-155, 2005

54. Saykin AJ, Gur RC, Sussman NM, O'Connor MJ, Gur RE: Memory deficits before and after temporal lobectomy: effect of laterality and age of onset. Brain Cogn 9:191-200, 1989

55. Schefft BK, Dulay MF, Fargo JD, Szaflarski JP, Yeh HS, Privitera MD: The use of self-generation procedures facilitates verbal memory in individuals with seizure disorders. Epilepsy Behav 13:162-168, 2008

56. Schwarz M, Pauli E, Stefan H: Model based prognosis of postoperative object naming in left temporal lobe epilepsy. Seizure 14:562-568, 2005

57. Seiam AH, Dhaliwal H, Wiebe S: Determinants of quality of life after epilepsy surgery: systematic review and evidence summary. Epilepsy Behav 21:441-445, 2011

58. Sherman EM, Wiebe S, Fay-McClymont TB, Tellez-Zenteno J, Metcalfe A, Hernandez-Ronquillo L, et al: Neuropsychological outcomes after epilepsy surgery: systematic review and pooled estimates. Epilepsia 52:857-869, 2011

59. Spencer S, Huh L: Outcomes of epilepsy surgery in adults and children. Lancet Neurol 7:525-537, 2008

60. Stone JJ, Reynolds MR, Leuthardt EC: Transient hemispatial neglect after surgical resection of a right frontal lobe mass. World Neurosurg 76:361.e7-361.e10, 2011

61. Tandon N, Alexopoulos AV, Warbel A, Najm IM, Bingaman WE: Occipital epilepsy: spatial categorization and surgical management. Clinical article. J Neurosurg 110:306-318, 2009

62. Trenerry MR, Jack CR Jr, Cascino GD, Sharbrough FW, Ivnik RJ: Gender differences in post-temporal lobectomy verbal memory and relationships between MRI hippocampal volumes and preoperative verbal memory. Epilepsy Res 20:69-76, 1995

63. Trenerry MR, Jack CR Jr, Ivnik RJ, Sharbrough FW, Cascino GD, Hirschorn KA, et al: MRI hippocampal volumes and memory function before and after temporal lobectomy. Neurology 43:1800-1805, 1993

64. Vaidya CJ, Gabrieli JD, Verfaellie M, Fleischman D, Askari N: Font-specific priming following global amnesia and occipital lobe damage. Neuropsychology 12:183-192, 1998

65. York MK, Rettig GM, Grossman RG, Hamilton WJ, Armstrong DD, Levin HS, et al: Seizure control and cognitive outcome after temporal lobectomy: a comparison of classic Ammon's horn sclerosis, atypical mesial temporal sclerosis, and tumoral pathologies. Epilepsia 44:387-398, 2003

Manuscript submitted November 17, 2011.

Accepted January 6, 2012.

Please include this information when citing this paper: DOI: 10.3171/2012.1.FOCUS11340.

Address correspondence to: Mario F. Dulay, Ph.D., The Methodist Neurological Institute, Neurosurgery, 6560 Fannin Street, Suite 944, Houston, Texas 77030. email: mdulay@tmhs.org. 